\title{
Vertical fracture resistance of roots retreated using different instrumentation techniques
}

\author{
Dilek Helvacıoğlu Yiğit, ${ }^{1}$ Ayça Yılmaz, ${ }^{2}$ Serkan Sarıdağ, ${ }^{3}$ Egemen Avcu,,${ }^{4}$ Yasemin Yıldıran ${ }^{5}$ \\ 'Department of Endodontics, Kocaeli University Faculty of Dentistry, Kocaeli, Turkey \\ ${ }^{2}$ Department of Endodontics, Istanbul University, Faculty of Dentistry, Istanbul, Turkey \\ ${ }^{3}$ Department of Prosthodontics, Kocaeli University Faculty of Dentistry, Kocaeli, Turkey \\ ${ }^{4}$ Ford Otosan Ihsaniye Automotive Vocational School, Kocaeli University, Kocaeli, Turkey \\ ${ }^{5}$ Department of Mechanical Engineering, Kocaeli University Faculty of Engineering, Kocaeli, Turkey
}

\begin{abstract}
Objective: The aim was to evaluate the resistance to vertical root fracture (VRF) of retreated roots using rotary and hand instrumentation.

Methods: Forty five extracted maxillary incisor teeth had their crowns removed to standardize the root lengths to $16 \mathrm{~mm}$. The root canals of the specimens were prepared using ProTaperUniversal (PTU) rotary instruments and obturated using the cold lateral condensation technique with gutta-percha and $\mathrm{AH}$ Plus sealer. Teeth were randomly allocated into three groups $(n=15)$. The first group was not retreated and served as a control group. The other two groups were retreated using either PTU retreatment instruments or hand-files, followed by obturation. The periodontal ligament of the filled roots was simulated. Specimens were embedded into self-curing acrylic and subjected to a vertically applied loading force $(1.0 \mathrm{~mm} / \mathrm{min})$ in a universal testing machine until the root fractured. The data were recorded in Newtons and statistically analyzed (Kruskal-Wallis and Dunn multiple comparison tests, $\mathrm{p}<0.05$ ).
\end{abstract}

Results: Retreated groups revealed had lower fracture resistances when compared with the control group $(p<0.05)$. However, the difference in the median values among the rotary and hand instrumentation groups was not significant.

Conclusion: Within the limitations of this study, VRF risk increases in retreated teeth regardless of the instrumentation technique used.

Keywords: Fracture resistance; retreatment, root canal theraphy; tooth fractures.

$\mathrm{T}$ he diagnosis and management of vertical root fracture $(\mathrm{VRF})$ presents a challenge in clinical dentistry. ${ }^{[1]}$ The prognosis of endodontically treated teeth having VRF is poor. Post-endodontic tooth fractures might occur due to loss of tooth structure and induced stresses caused by endodontic and restorative treatment procedures, to include: access preparation, root canal preparation, irriga- tion, compaction of filling materials, post-space preparation, post selection and coronal restoration. ${ }^{[2]}$ Excess removal of sound tooth structure during instrumentation may increase the susceptibility to $\mathrm{VRF}^{[3]}$ Retreatment procedures, on the other hand, might cause more damage to the root canal wall and weaken the root canal with further biomechanical preparation. ${ }^{[4]}$ Furthermore, the alterations

Correspondence: Dr. Ayça Yılmaz. İstanbul Üniversitesi Diş Hekimliği Fakültesi,

Endodonti Anabilim Dalı, Çapa, Fatih İstanbul, Turkey.

Tel: +90 532 - 5163400 e-mail: aycasimsek@gmail.com

Submitted: November 24, 2015 Accepted: December 06, 2015 
in the mechanical features of dentin, such as: stiffening, low plasticity due to dehydration, decreased strength and toughness due to microbe-induced degradation, or modification of collagen, predispose endodontically treated teeth to fracture. ${ }^{[5]}$

An in vitro fracture resistance test can be used to investigate the strength of teeth and is an easy to handle and comparable outcome parameter. This test subjects teeth to continuous forces until fracture and the forces at failure are recorded. ${ }^{[6,7]}$

Non-surgical retreatment is the preferred treatment option for most cases with signs of disease after the initial root canal filling. ${ }^{[8]}$ Efficient removal of the existing root canal filling materials is essential for optimal non-surgical retreatment. Some Ni-Ti rotary instruments have been developed for these retreatment procedures. The application of rotary $\mathrm{Ni}-\mathrm{Ti}$ instruments for retreatment has been shown to be safe, efficient and time saving. ${ }^{[9,10]}$ The Protaper Universal retreatment (PTU-R) system consists of three instruments: Dl with a 30 tip, taper of 0.09 and a length of $16 \mathrm{~mm}, \mathrm{D} 2$ with a 25 tip, taper of 0.08 and a length of $18 \mathrm{~mm}$ and D3 with a 20 tip, taper of 0.07 and a length of $22 \mathrm{~mm}$. The files have a convex, triangular cross section and the Dl instrument has an active tip that penetrates into the root filling material, facilitating the removal of the material.

Most of current literature contains studies about the effect of various nickel-titanium rotary files on root dentin and fracture formation. Some studies have reported an increased risk for dentin defects and reduced root fracture resistance when compared with using hand files. ${ }^{[2]} \mathrm{Ni}-\mathrm{Ti}$ retreatment systems provide minimal dentin loss of root canals during filling removal. However, there are not sufficient studies on Ni-Ti retreatment systems and their effect on the fracture resistance of roots. Therefore, the aim of this study was to assess the resistance to vertical root fracture (VRF) of roots retreated using rotary and hand instrumentation. The null hypothesis was that there would be no significant difference in the resistance to VRF between these treatment modalities.

\section{Materials and methods}

\section{Preparation of samples}

Ninety freshly extracted maxillary anterior teeth with single, straight roots and intact root apices were obtained from the collections of the Department of Oral and Maxillofacial Surgery Kocaeli University. One observer, using a light microscope (IX70, Olympus Optical Co. Ltd, Tokyo, Japan) under 15-40X magnification, selected 45 teeth with no cracks or fractures on the external root sur- faces. The teeth were decoronated to standardize the root lengths to $16 \mathrm{~mm}$ and the specimens were then stored in $0.1 \%$ thymol solution.

\section{Instrumentation and obturation}

A \#10 K-file (Mani Inc., Tochigi-Ken, Japan) was placed passively in each root canal until it reached the apical foramen. The working length was recorded as $0.5 \mathrm{~mm}$ shorter than the measured length. Root canals of specimens were prepared using the ProTaper Universal (PTU) rotary instruments up to size 30 (F3), operated with a torque-limited motor (VDW silver, VDW, Munich, Germany). The root canals were irrigated with $2 \mathrm{~mL}$ of $1 \% \mathrm{NaOCl}$ solution after each instrument change using a syringe and a 27 -gauge needle. Following instrumentation, each canal was irrigated with $5 \mathrm{~mL}$ of $17 \%$ EDTA, $5 \mathrm{~mL}$ of $1 \% \mathrm{NaO}$ $\mathrm{Cl}$ and a final rinse of $5 \mathrm{~mL}$ distilled water. The root canals were dried with paper points (Diadent, Seoul, Korea). AH Plus sealer (DeTrey Dentsply, Kontanz, Germany) was mixed according to the manufacturer's instructions and introduced into the canal by using a lentulo spiral (Mani Inc., Tochigi-Ken, Japan). Main \#30 gutta-percha cones with a taper of 0.02 (Diadent, Seoul, Korea) were coated with sealer and placed into the root canal, up to the working length. Root canals were obturated using the cold lateral condensation technique with accessory gutta-percha cones and \#25 finger spreaders (Mani Inc., Tochigi-Ken, Japan) until the canal was completely obturated. Excess root filling in the coronal portion was removed $1 \mathrm{~mm}$ below the cementoenamel junction and vertically condensed with a heated plugger. The canal openings were sealed with temporary filling material (Cavit; $3 \mathrm{M}$ ESPE, Seefeld, Germany). Teeth were stored at $37^{\circ} \mathrm{C}$ with $100 \%$ humidity for one week to allow the sealer to set.

\section{Retreatment}

Teeth were randomly allocated into three groups $(n=15)$. The first group was not retreated to serve as a control group. The other two groups were retreated, as follows:

In the Protaper Universal retreatment (PTU-R) group, the root canal filling was removed using PTU-R files (DI, D2, D3) by the crown down technique until the working length was reached. The final apical preparation was then completed using the F2, F3 and F4 PTU instruments. The instruments were used with a torque-limited electric motor in the "PTU" mode. The rotational speed and the torque limit of the instruments was programmed in the file library of the motor.

In the hand instrumentation group, the coronal root filling was removed using size 2 and 3 Gates-Glidden burs 
(Mani Inc., Tochigi-Ken, Japan). Hand instrumentation was carried out using size 25,30, 35 and 40 Hedström files (Mani Inc., Tochigi-Ken, Japan) in a circumferential quarter-turn push-pull filling motion.

The canals were constantly irrigated with $1 \% \mathrm{NaOCl}$ during root canal re-treatment. The removal of the root filling was judged to be complete when the working length was reached and no filling material was detected on the instrument surfaces when withdrawn from the canal. All canals were finally irrigated with $5 \mathrm{~mL}$ of 17\% EDTA, $5 \mathrm{~mL}$ of $1 \% \mathrm{NaOCl}$ and $5 \mathrm{~mL}$ distilled water. The root canals were dried with paper points.

Root canals were obturated using the cold lateral condensation technique with gutta-percha and AHPlus sealer as previously described. The coronal access was sealed using glass ionomer cement (Ketac, 3M, ESPE Dental AG, Seefeld, Germany) and specimens were stored in 100\% humidity at $37{ }^{\circ} \mathrm{C}$ for one week. One operator performed all of the root canal cleaning, shaping, obturation and retreatment procedures to avoid inter-operator variability.

\section{Mounting of roots and mechanical testing}

The filled roots were covered with a $0.2 \mathrm{~mm}$-thick layer of a polyether material (Impregum Garant L Duosoft, 3M ESPE, Seefeld, Germany) to simulate the human periodontium. Each sample was embedded $1.0 \mathrm{~mm}$ apical to the cementoenamel junction in a self-curing acrylic resin block (Meliodent, Heraeus Kulzer, Hanau, Germany). Artificial tooth mobility was evaluated in horizontal and vertical directions using a periotest instrument (Periotest, Siemens AG, Bensheim, Germany). Periotest values of the embedded teeth were standardized at a value of $<7$ to simulate the natural dentition. Teeth were subjected to a loading force $(1.0 \mathrm{~mm} / \mathrm{min})$ using a plunger with a 2 $\mathrm{mm}$ diameter rounded tip applied vertically in a universal testing machine (Instron Corp., Canton, MA) until the root fractured (Figure 1). The data were recorded in Newtons. The pattern and direction of fractures were also noted.

\section{Statistical analysis}

The statistical analyses were performed using SPSS 20 (IBM, Armonk, NY, USA) pocket program. The Kolmogorov-Smirnov test revealed that the data was not normally distributed. The Kruskal-Wallis test was applied to compare the groups, followed by Dunn's multiple comparison test to compare subgroups, both at a significance level of $5 \%$.

\section{Results}

The Kruskal-Wallis test revealed a significant difference between the groups $(\mathrm{H}=28.81, \mathrm{p}>0.001)$. The mean and median forces required to vertically fracture the roots and standard deviation values for the three groups are presented in Table 1. The lowest mean force to fracture was found in the hand instrumentation group $(718.2 \mathrm{~N})$. When a multiple comparison procedure was used, retreated groups revealed significantly lower fracture resistance
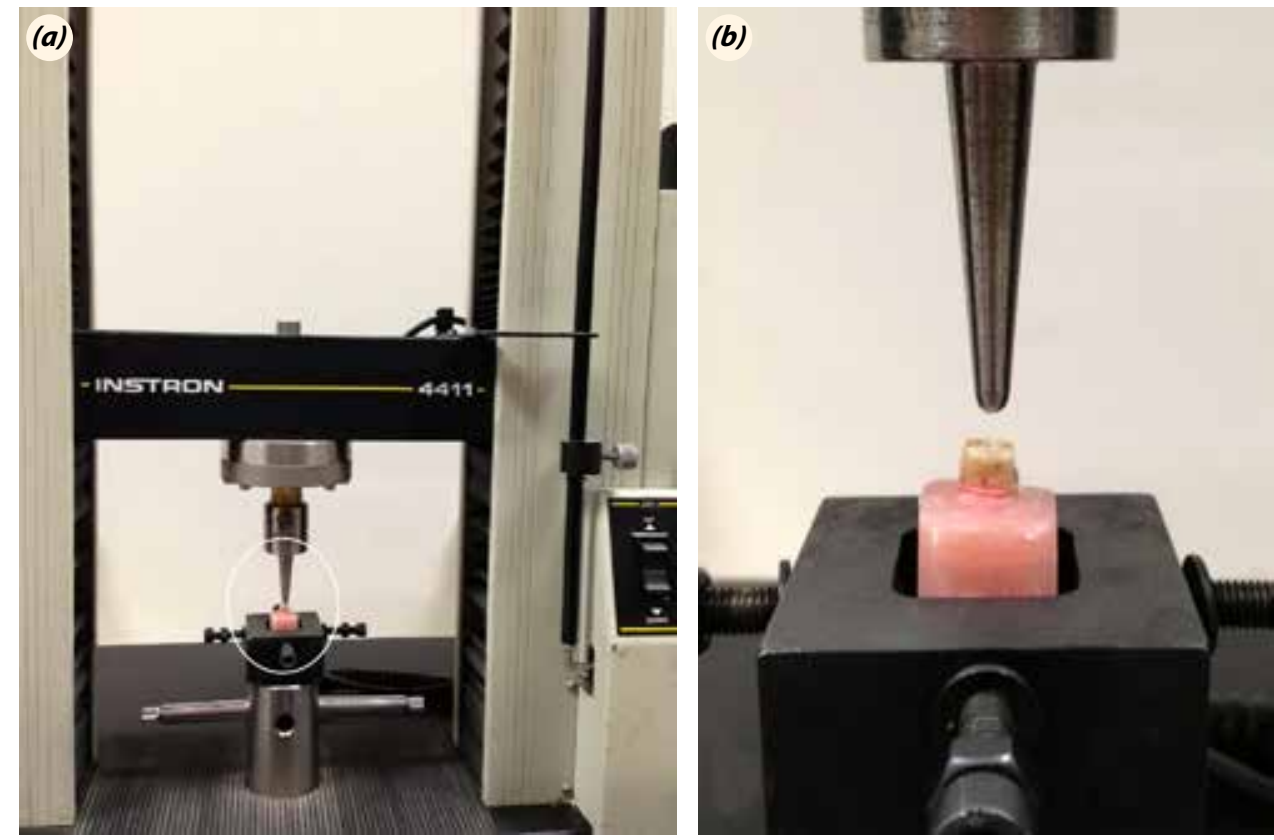

Fig. 1. (a) Fracture strength test (b) Circled area:Test specimen mounted on the universal testing machine prior to loading. 
Table 1. Mean, median and standard deviation values of force required for fracture of each group after retreatment

\begin{tabular}{lcc} 
Groups & Median (25\%-75\% Percentage) & Mean force for vertical fracture (N) \pm SD \\
Retreatment with hand files $(n=15)$ & $742(678-770)$ & $718.2 \pm 58.23$ \\
Retreatment with rotary files $(n=15)$ & $760(701.25-831)$ & $765.47 \pm 68.09$ \\
No retreatment $(n=15)$ & $905(872.50-942.50)$ & $921.33 \pm 87.42$ \\
\hline
\end{tabular}

Table 2. Multiple comparison test of groups

\begin{tabular}{lc} 
Dunn's multiple comparison test & Difference of ranks \\
\hline Group 1/Group 2 & 24.095 \\
Group 1/Group 3* & 19.067 \\
Group 2/Group 3* & 5.029 \\
\hline
\end{tabular}

${ }^{*} p<0.05$

of roots compared with the control group $(\mathrm{p}<0.05)$. However, the difference in the median values between the rotary and hand instrumentation groups was not significant (Table 2).

Two fracture patterns (split and comminuted) and three directions of fracture lines (bucco-lingual, mesiodistal and combined) were detected. The distribution of fracture patterns and directions are shown in Figure 2. Combined fracture occurred more commonly than did the bucco-lingual and mesio-distal fractures in all groups. None of the roots in the hand file group fractured in the bucco-lingual direction. In 25 of 45 roots, the comminuted fracture pattern was observed, whereas 20 of 45 roots displayed split fractures.

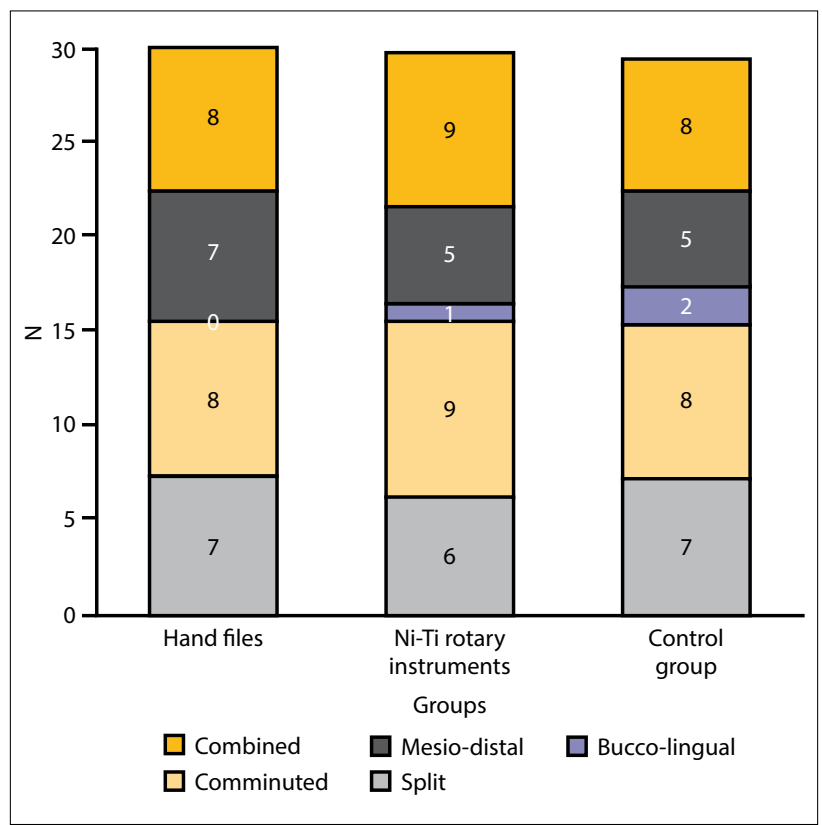

Fig. 2. Distribution of fracture patterns and directions of fracture lines within each group.

\section{Discussion}

The incidence of VRF is higher in root canal treated teeth. ${ }^{[11]}$ This is mostly attributed to localized stresses along the inner dentin walls relating to endodontic treatment procedures or further clinical treatments such as post placement. ${ }^{[12]}$ Mechanical instrumentation may contribute to VRF formation by initiating cracks which can cause potential stress areas. Retreatment procedures, on the other hand, are more destructive to dentin with the additional widening of the root canal to remove the previous filling material. ${ }^{[13]}$ Moreover, the removal of posts or fractured instruments may weaken the structural integrity of a tooth, making it more susceptible to fracture. Hence, excessive and aggressive instrumentation of a root canal should be avoided during retreatment procedures. ${ }^{[14]}$ To date, there are a limited number of studies on the effect of re-instrumentation techniques on the fracture resistance of retreated roots. ${ }^{[14,15]}$ Two retreatment techniques have been compared in the present study and no significant difference was found between them. Hence, the null hypothesis is accepted. However, the retreated groups revealed decreased fracture resistance when compared with the control group. The higher risk of VRF of retreated roots when compared with root canal treated or not treated teeth is in agreement with previous studies. ${ }^{[4,16]}$

Resistance to fracture is an important consideration in endodontics and in subsequent restoration and function. The load required to fracture the root provides an indication of fracture susceptibility of the root when subjected to forces encountered during restoration and clinical function. Destructive testing predominantly uses static loading to test the maximum load capability. The crosshead speed is a crucial parameter of static loading. ${ }^{[17]}$ The fracture resistance increases as crosshead speeds decreases, ${ }^{[18]}$ and speeds up to $150 \mathrm{~mm} / \mathrm{min}^{[19]}$ are an approximation of traumatic effects. Therefore, a crosshead speed of $1 \mathrm{~mm} /$ min was recommended. ${ }^{[6]}$ The relevance of this in vitro test to predict the clinical performance of retreated teeth using different instrumentation techniques lies in its ability to validate with respective controlled clinical trials.

Necrotic tissue or bacteria covered by remaining filling material in the root canal might be responsible for periapical inflammation or pain. Moreover, remnants of the 
root filling materials can potentially impair disinfection by preventing direct contact of chemical disinfectants with persisting microorganisms. ${ }^{[20]}$ As much filling material as possible should be removed to allow for adequate root canal preparation, disinfection, and subsequent re-filling of the entire root canal system. ${ }^{[21]}$ This task usually can be accomplished with hand files or Ni-Ti rotary instruments. The use of hand files can be a time-consuming process, especially when removing a well-condensed root filling. ${ }^{[22]} \mathrm{Ni}-\mathrm{Ti}$ rotary instruments, on the contrary, might be more effective and time saving during retreatment. ${ }^{[23]}$ The PTU-R technique has been proposed for removing root filling material and performing effective debridement and shaping of the root canal. The Dl instrument has been designed to facilitate the initial penetration into the filling material with the aid of its active tip.

In ex vivo retreatment studies, root canals are prepared and filled under standardized conditions, thus eliminating variables, such as: different working lengths or different final apical sizes. ${ }^{[24,25]}$ It has also been reported that the instrument size used during retreatment should be at least one size more than initial preparation size in order to achieve effective filling removal, especially in the apical part of the canal. ${ }^{[26-28]}$ In the present study, the root canal was enlarged using instruments one size bigger than the first instrumentation size.

VRF is predominantly attributed to increased stress concentration within the root canal. The anatomical factors, such as: canal shape, root shape, and dentin thickness, affects the root strength as well as the direction of possible root fracture. Lertchirakarn et al. ${ }^{[29]}$ reported that, when the proximal dentin thickness has been reduced, greater stress will be generated bucco-lingually. It has been demonstrated that a round canal shape has minimal stress concentration areas, distributing the stress uniformly ${ }^{[29,30]}$ Therefore, the pattern of fracture might be less predictable in round canals, although cracks can be induced anywhere around a smooth round canal surface. ${ }^{[31]}$ In the present study, bucco-lingual fractures were the least common among all groups. On the other hand, combined fractures were the most common detected fractures. This may be attributed to the round canal shape of maxillary anterior teeth and the uniformly distributed stresses on the root canal surface.

The current results demonstrated that roots prepared using PTU-R and hand instrumentation showed similar fracture resistance. Nevertheless, both groups were significantly less resistant to fracture when compared to the control group. This finding was in agreement with Wilcox et al., ${ }^{[32]}$ who demonstrated that roots are more likely to fracture when more root dentin was removed. Ganesh et al. ${ }^{[14]}$ evaluated the fracture resistance of teeth retreated using rotary instruments. Those authors' findings demonstrated that endodontically retreated teeth were less resistant to fracture. ${ }^{[14]}$ Topçuoğlu et al. ${ }^{[33]}$ and Shemesh et al. ${ }^{[4]}$ found that the number of dentinal defects in retreatment groups were higher than those found in filled or unreatreated groups. In the present study, the finding of lower fracture resistance in both retreatment groups when compared to the control group is in agreement with all these studies, suggesting that additional mechanical procedures or increased dentin removal leads to teeth that are more prone to fracture.

\section{Conclusion}

Within the limitations of this study, the fracture resistance of retreated roots was lower when compared to the fracture resistance of the non-retreated roots, regardless of the instrumentation technique used.

Conflics of Interest: No conflicts declared.

\section{References}

1. Tamse A. Iatrogenic vertical root fractures in endodontically treated teeth. Endod Dent Traumatol 1988;4:190-6.

2. Tang $\mathrm{W}, \mathrm{Wu} \mathrm{Y}$, Smales RJ. Identifying and reducing risks for potential fractures in endodontically treated teeth.J En$\operatorname{dod} 2010 ; 36: 609-17$.

3. Joyce AP, Loushine RJ, West LA, Runyan DA, Cameron SM. Photoelastic comparison of stress induced by using stainless-steel versus nickel-titanium spreaders in vitro. J Endod 1998;24:714-5.

4. Shemesh H, Roeleveld AC, Wesselink PR, Wu MK. Damage to root dentin during retreatment procedures. J Endod 2011;37:63-6.

5. Kishen A. Mechanisms and risk factors for fracture predilection in endodontically treated teeth. Endodontic Topics 2006;13:57-83.

6. Naumann M, Metzdorf G, Fokkinga W, Watzke R, Sterzenbach $\mathrm{G}$, Bayne $\mathrm{S}$, et al. Influence of test parameters on in vitro fracture resistance of post-endodontic restorations: a structured review. J Oral Rehabil 2009;36:299-312.

7. EL-Máaita AM, Qualtrough AJ, Watts DC. Resistance to vertical fracture of MTA-filled roots. Dent Traumatol 2014;30:36-42.

8. Friedman S. Considerations and concepts of case selection in the management of post-treatment endodontic disease. Endodontic Topics 2002;1:54-78.

9. Hülsmann M, Bluhm V. Efficacy, cleaning ability and safety of different rotary NiTi instruments in root canal retreatment. Int Endod J 2004;37:468-76.

10. Schirrmeister JF, Hermanns P, Meyer KM, Goetz F, Hellwig E. Detectability of residual Epiphany and gutta-percha 
after root canal retreatment using a dental operating microscope and radiographs--an ex vivo study. Int Endod J 2006;39:558-65.

11. Fuss Z, Lustig J, Katz A, Tamse A. An evaluation of endodontically treated vertical root fractured teeth: impact of operative procedures. J Endod 2001;27:46-8.

12. Lertchirakarn V, Palamara JE, Messer HH. Finite element analysis and strain-gauge studies of vertical root fracture. J Endod 2003;29:529-34.

13. Karygianni L, Krengel M, Winter M, Stampf S, Wrbas KT. Comparative assessment of the incidence of vertical root fractures between conventional versus surgical endodontic retreatment. Clin Oral Investig 2014;18:2015-21.

14. Ganesh A, Venkateshbabu $N^{1}$, John $A^{1}$, Deenadhayalan $\mathrm{G}^{1}$, Kandaswamy D1. A comparative assessment of fracture resistance of endodontically treated and re-treated teeth: An in vitro study. J Conserv Dent 2014;17:61-4.

15. Er K, Tasdemir T, Siso SH, Celik D, Cora S. Fracture resistance of retreated roots using different retreatment systems. Eur J Dent 2011;5:387-92.

16. Yoldas O, Yilmaz S, Atakan G, Kuden C, Kasan Z. Dentinal microcrack formation during root canal preparations by different $\mathrm{NiTi}$ rotary instruments and the self-adjusting file. J Endod 2012;38:232-5.

17. Farik B, Munksgaard EC. Fracture strength of intact and fragment-bonded teeth at various velocities of the applied force. Eur J Oral Sci 1999;107:70-3.

18. Baratieri LN, De Andrada MA, Arcari GM, Ritter AV. Influence of post placement in the fracture resistance of endodontically treated incisors veneered with direct composite. J Prosthet Dent 2000;84:180-4.

19. Dean JP, Jeansonne BG, Sarkar N. In vitro evaluation of a carbon fiber post. J Endod 1998;24:807-10.

20. Sen BH, Safavi KE, Spångberg LS. Antifungal effects of sodium hypochlorite and chlorhexidine in root canals. J Endod 1999;25:235-8.

21. Gordon MP. The removal of gutta-percha and root canal sealers from root canals. N Z Dent J 2005;101:44-52.

22. de Oliveira DP, Barbizam JV, Trope M, Teixeira FB. Comparison between gutta-percha and resilon removal using two different techniques in endodontic retreatment. J En- $\operatorname{dod} 2006 ; 32: 362-4$.

23. Helvacioglu-Yigit D, Yilmaz A, Kiziltas-Sendur G, Aslan OS, Abbott PV. Efficacy of reciprocating and rotary systems for removing root filling material: a micro-computed tomography study. Scanning 2014;36:576-81.

24. Gu LS, Ling JQ, Wei X, Huang XY. Efficacy of ProTaper Universal rotary retreatment system for gutta-percha removal from root canals. Int Endod J 2008;41:288-95.

25. Gergi R, Sabbagh C. Effectiveness of two nickel-titanium rotary instruments and a hand file for removing gutta-percha in severely curved root canals during retreatment: an ex vivo study. Int Endod J 2007;40:532-7.

26. Hülsmann M, Drebenstedt S, Holscher C. Shaping and filling root canals during root canal re-treatment. Endodontic Topics 2008;19:74-124.

27. Roggendorf MJ, Legner M, Ebert J, Fillery E, Frankenberger R, Friedman S. Micro-CT evaluation of residual material in canals filled with Activ GP or GuttaFlow following removal with $\mathrm{NiTi}$ instruments. Int Endod J 2010;43:200-9.

28. Hassanloo A, Watson P, Finer Y, Friedman S. Retreatment efficacy of the Epiphany soft resin obturation system. Int Endod J 2007;40:633-43.

29. Lertchirakarn V, Palamara JE, Messer HH. Patterns of vertical root fracture: factors affecting stress distribution in the root canal. J Endod 2003;29:523-8.

30. Versluis A, Messer HH, Pintado MR. Changes in compaction stress distributions in roots resulting from canal preparation. Int Endod J 2006;39:931-9.

31. Sathorn C, Palamara JE, Messer HH. A comparison of the effects of two canal preparation techniques on root fracture susceptibility and fracture pattern. J Endod 2005;31:2837.

32. Wilcox LR, Roskelley C, Sutton T. The relationship of root canal enlargement to finger-spreader induced vertical root fracture. J Endod 1997;23:533-4.

33. Topçuoğlu HS, Demirbuga S, Tuncay Ö, Pala K, Arslan $\mathrm{H}$, Karataş E. The effects of Mtwo, R-Endo, and D-RaCe retreatment instruments on the incidence of dentinal defects during the removal of root canal filling material. J Endod 2014;40:266-70. 